\title{
THE GALVANOSTATIC SINGLE-PULSE AND THE COULOSTATIC IMPULSE METHODS FOR THE DETERMINATION OF THE RATE CONSTANTS OF ELECTRODE REACTIONS*
}

\author{
D. J. Kooljman and J. H. SluYters \\ Laboratory of Analytical Chemistry, State University, Utrecht, Netherlands
}

\begin{abstract}
The information on kinetic parameters of electrode reactions obtained with the galvanostatic single-step, the coulostatic impulse and the faradaic impedance methods is examined as a function of the applied electrolysis time and the ac frequency. A time and a frequency condition is given for which the information on kinetics obtainable with these methods is maximal. In the usual approach to the single-step and the coulostatic impulse methods these optimal conditions cannot be met. We present here a new procedure with which the experimental data measured with both methods can be interpreted exactly over the whole region of the $\eta / t$ curve by means of numerical tables. The application of these tables enhances the limit of the applicability of the single-step method by a factor of 3 and that of the coulostatic impulse method by a factor of 100 . The methods are applied to the $\mathrm{Cd}^{2+} / \mathrm{Cd}(\mathrm{Hg})$-electrode in $1 \mathrm{M} \mathrm{NaClO}_{4}$ and the $\mathrm{Hg}_{2}{ }^{2}+\mathrm{Hg}$ electrode in $1 \mathrm{M} \mathrm{HClO}$.
\end{abstract}

Résumé-Les informations concernant les paramètres cinétiques des réactions de transfert d'électrode, obtenus suivant les méthodes de courant galvanostatique, d'impulsion coulostatique et d'impédance faradique sont examinés en fonction de la durée de l'électrolyse et de la fréquence. Il s'ensuit une condition propre à la durée et á la fréquence, pour laquelle le renseignement cinétique est maximal. Normalement, avec les méthodees de courant galvanostatique et d'impulsion coulostatique, ces conditions optimales ne peuvent être remplies. C'est pourquoi, dans cet article, nous présentons un nouveau procédé, á l'aide duquel les données expérimentales, mesurées suivant les deux méthodes, peuvent être exactement interpretées pour le domaine entier de la courbe $\eta / t$ en utilisant des tableaux, numériques. L'utilisation de ces tableaux multiplie la limite d'applicabilité de la méthode de courant galvanostatique par un facteur de trois et celle de la méthode d'impulsion coulostatique par un facteur de cent. Les méthodes ont été appliquées à l'électrode $\mathrm{Cd}^{2+} / \mathrm{Cd}(\mathrm{Hg})$ dans $1 \mathrm{M} \mathrm{NaClO}$. et à l'électrode $\mathrm{Hg}_{2}{ }^{2+} / \mathrm{Hg}$ dans $1 \mathrm{M} \mathrm{HClO}_{4}$.

Zusammenfassumg-Die über die kinetischen Parameter von Elektrodenreaktionen aus galvanostatischen Einschaltverfahren, mit der coulostatischen Impulsmethode und mit der Methode der Faraday-Impedanz erhältliche Information wird in Hinblick auf ihre Abhängigkeit von der Elektrolysezeit und der Wechselspannungsfrequenz untersucht. Man gibt Bedingungen für Zeit und Frequenz, bei welchen die ermittelbare Information maximal ist. Bei den üblichen Anwendungen der Einschaltund der coulostatischen Impulsmethode können diese optimalen Bedingungen nicht erreicht werden. Es wird eine neue Auswertetechnik vorgeschlagen, bei der die mit beiden Methoden gemessenen experimentellen Daten über den ganzen Bereich der Ueberspannungs/Zeitkurve mit Hilfe von numerischen Tabellen genau interpretiert werden können. Die Verwendung dieser Tabellen verschiebt die Grenze der Anwendbarkeit der Einschaltmethode um einen Faktor von 100. Anwendungen der Methoden auf die $\mathrm{Cd}^{2+} / \mathrm{Cd}(\mathrm{Hg})$-Elektrode in $1 \mathrm{M} \mathrm{NaClO}$ und die $\mathrm{Hg}_{2}{ }^{2+} / \mathrm{Hg}$-Elektrode in $1 \mathrm{M} \mathrm{HClO}_{4}$ werden beschrieben.

\section{INTRODUCTION}

THE STUDY of the kinetics of fast clectrode reactions requires high rates of mass transfer of reactants to minimize mass-transfer polarization. In relaxation methods high rates of mass-transfer with diffusion as the sole mass-transfer process require measurements either of short duration or at high frequencies. For instance, ${ }^{1}$ the electrolysis time at measurements with the galvanostatic step method must be chosen so short that the average velocity of the diffusing reactants, $\bar{v}=2 \sqrt{ }(D / \pi t)$, is comparable with the velocity, $k_{\mathrm{sh}}$, of the charge-transfer process. However, the presence

* Manuscript received 28 September 1966. 
of the double-layer capacitance prevents the application of signals of short duration or high frequencies. Therefore there must be an optimal time-frequency condition for which the kinetic parameters can be best evaluated. In this paper these conditions will be examined for the galvanostatic step, the coulostatic impulse and the faradaic impedance methods. It appears that these theoretical optimal conditions cannot be fulfilled in the usual approach to the galvanostatic step and the coulostatic impulse methods. It will be shown that the limitations of these methods can be overcome by a numerical approach by means of nomograms.

TIME DEPENDENCY OF THE INFORMATION ON THE KINETIC

PARAMETERS IN THE GALAVANOSTATIC STEP METHOD

If a current impulse $i$, represented by a step function, passes through the electrode/ solution interface, the overvoltage $\eta$ will be in general

$$
\eta=f\left(i, t, R_{\Omega}, C_{\mathrm{d}}, D, i_{0}, C^{*}\right) \text {. }
$$

The exchange current density, $i_{0}$, can be evaluated exactly, at least in principle, if all the other parameters in (1) (in which the symbols have their usual significance) are known exactly. In practice the parameters in (1) will be known with some inaccuracy and consequently the evaluated exchange current density will have an error, $d i_{0}$,

$$
d i_{0}=\frac{d \eta-\frac{\partial \eta}{\partial C_{\mathrm{d}}} d C_{\mathrm{d}}-\frac{\partial \eta}{\partial D} \mathrm{~d} D}{\frac{\partial \eta}{\partial i_{0}}}
$$

in which $\mathrm{d} i, \mathrm{~d} C^{*}$ and $\mathrm{d} t$ are assumed to be zero and the error $\Delta R_{\Omega}$, due to miscompensation of $R_{\Omega}$, is reflected in $\mathrm{d} \eta$.

In (2) the errors are absolute, whereas one always uses relative errors, so

$$
\frac{\mathrm{d} i_{0}}{i_{0}}=\frac{\frac{\mathrm{d} \eta}{\eta}-\frac{\partial \eta}{\partial C_{\mathrm{d}}} \frac{\mathrm{d} C_{\mathrm{d}}}{\eta}-\frac{\partial \eta}{\partial D} \frac{\mathrm{d} D}{\eta}}{\frac{i_{0}}{\eta} \frac{\partial \eta}{\partial i_{0}}}
$$

For the sake of simplicity we will first assume that $d C_{\mathrm{d}}=\mathrm{d} D=0$; then

$$
\frac{\mathrm{d} i_{0}}{i_{0}}=\frac{\frac{\mathrm{d} \eta}{\eta}}{\frac{i_{0}}{\eta} \frac{\partial \eta}{\partial i_{0}}}
$$

In that case maximum information on $i_{0}$ is obtained, if the denominator in (2b) is maximal, ie for the time condition

$$
\frac{\mathrm{d}}{\mathrm{d} t}\left(\frac{i_{0}}{\eta} \frac{\partial \eta}{\partial i_{0}}\right)=0
$$

This equation must be solved after insertion of the explicit solution of $\eta$ as a function 
of $t$ derived by Delahay and Berzins ${ }^{2}$,

where

$$
\eta(t)=\frac{i}{C_{\mathrm{d}}(\gamma-\beta)}\left[\begin{array}{c}
\gamma / \beta^{2}\left(\exp \beta^{2} t \operatorname{erfc} \beta \sqrt{ } t+2 \beta /\left(\frac{t}{\pi}\right)-1\right) \\
-\beta / \gamma^{2}\left(\exp \gamma^{2} t \operatorname{erfc} \gamma \sqrt{ } t+2 \gamma /\left(\frac{t}{\pi}\right)-1\right)
\end{array}\right],
$$

$$
\beta \gamma=\frac{n F i_{0}}{R T C_{\mathrm{d}}} \text { and } \beta+\gamma=\frac{i_{0}}{n F}\left(\frac{1}{C_{\mathrm{Ox}}{ }^{*} \sqrt{ } D_{\mathrm{Ox}}}+\frac{1}{C_{\mathrm{Rcd}}^{*} \sqrt{ } D_{\mathrm{Rcd}}}\right) \text {. }
$$

An exact solution for (3) in combination with (4) could not be found. Therefore we have solved the problem numerically with tables ${ }^{3}$ of the exp erfc occurring in (4). For this purpose (4) has been written in a dimensionless form by substituting $t=k / a^{2}$, in which $a$ is $\beta \gamma /(\beta+\gamma)$, having a dimension $t^{-1 / 2}$, and $k$ is a dimensionless parameter. The advantage is that (4) written in such a form is dependent only on $k$ and the also dimensionless parameter $(\beta+\gamma)^{2} / \beta \gamma$, as can be shown by expansion of (4) for long and short times.

For long times, ie large values of $k$,

$\frac{a^{2} C_{\mathrm{d}} \eta}{i}=\frac{\beta \gamma}{(\beta+\gamma)^{2}}\left[1-\frac{(\beta+\gamma)^{2}}{\beta \gamma}+2 \frac{(\beta+\gamma)^{2}}{\beta \gamma} \frac{k^{1 / 2}}{\pi^{1 / 2}}+\left(\frac{(\beta+\gamma)^{2}}{\beta \gamma}-2\right) \frac{1}{\pi^{1 / 2} k^{1 / 2}}+\ldots\right]$,

and for short times, ie small values of $k$,

in which

$$
\frac{a^{2} C_{\mathrm{d}} \eta}{i}=k\left[1-\frac{1}{2} \frac{(\beta+\gamma)^{2}}{\beta \gamma} k+\frac{4}{15 \pi^{1 / 2}} \frac{(\beta+\gamma)^{4}}{\beta^{2} \gamma^{2}} k^{2}+\ldots\right],
$$

$$
a=\beta \gamma /(\beta+\gamma)=\frac{n^{2} F^{2}}{R T C_{\mathrm{d}}}\left(\frac{1}{C_{\mathrm{Ox}}{ }^{*} \sqrt{ } D_{\mathrm{Ox}}}+\frac{1}{C_{\mathrm{Red}}^{*} \sqrt{ } D_{\mathrm{Red}}}\right)^{-1} .
$$

In (5a) and (5b) only the quantity $(\beta+\gamma)^{2} / \beta \gamma$ depends on $i_{0}$. This means that only the value of $(\beta+\gamma)^{2} / \beta \gamma$ and not $i_{0}$ itself of the system under examination determines whether or not the exchange current density can be evaluated with the galvanostatic step method. It will be shown below that the quantity $(\beta+\gamma)^{2} / \beta \gamma$ also determines the applicability of the coulostatic impulse method and of the faradaic impedance method. In the latter method we prefer to use the notation $2 \sigma^{2} C_{d} / \theta$, which is identical to $(\beta+\gamma)^{2} / \beta \gamma$.

For instance, the rate constant $k_{\mathrm{sh}}$ of the system $\left(k_{\mathrm{Bh}}=1 \mathrm{~cm} / \mathrm{s}, C_{\mathrm{Ox}}{ }^{*}=C_{\mathrm{Red}}^{*}=\right.$ $10^{-5} / \mathrm{mol} / \mathrm{cm}^{3}, D_{0 \mathrm{x}}=D_{\mathrm{Red}}=10^{-5} \mathrm{~cm}^{2} / \mathrm{s}, C_{\mathrm{d}}=10^{-5} \mathrm{~F} / \mathrm{cm}^{2}$ and $\left.n=1\right)$ is in theoretical aspect as hard to obtain with the three methods as the $k_{\mathrm{sh}}$ of the system $\left(k_{\mathrm{sh}}=\right.$ $4.10^{-4} \mathrm{~cm} / \mathrm{s}, C_{0 \mathrm{x}}{ }^{*}=C_{\mathrm{Red}}^{*}=10^{-7} \mathrm{~mol} / \mathrm{cm}^{3} D_{\mathrm{Ox}}=D_{\text {Red }}=4.10^{-6} \mathrm{~cm}^{2} / \mathrm{s} . C_{\mathrm{d}}=10^{-4}$ $\mathrm{F} / \mathrm{cm}^{2}$ and $\left.n=1\right)$, since for both systems the value of $(\beta+\gamma)^{2} / \beta \gamma$ is $0 \cdot 1$. Experimental circumstances for the determination of the $i_{0}$ of these systems, however, will greatly differ. The first system should be perturbed with signals in the $\mu$ s range or $\mathrm{MHz}$ frequencies, and the latter with signals in the s range or Hx frequencies. Moreover compensation of ohmic drop for the first system is more critical than for the latter.

In view of the importance of the quantity $(\beta+\gamma)^{2} / \beta \gamma$ we have solved (3) in combination with (4) numerically for different values of $(\beta+\gamma)^{2} / \beta \gamma$. The results are 
graphically presented in Fig. 1. From this figure it can be seen that the maxima of the curves occur when $\beta \gamma t \sim 4$, remarkably independent of the $(\beta+\gamma)^{2} / \beta \gamma$ value. Therefore, on the basis of (2b) alone, maximum information on the exchange current density will be obtained from measurements with the galvanostatic step method at a pulse time $t$ where

$$
t \sim 4 / \beta \gamma .
$$

The influence of errors due to the uncertainties in the diffusion coefficients $(\mathrm{d} D)$ and in the double layer capacitance $\left(\mathrm{d} C_{\mathrm{d}}\right)$, see $(2 \mathrm{a})$, has been examined also. It

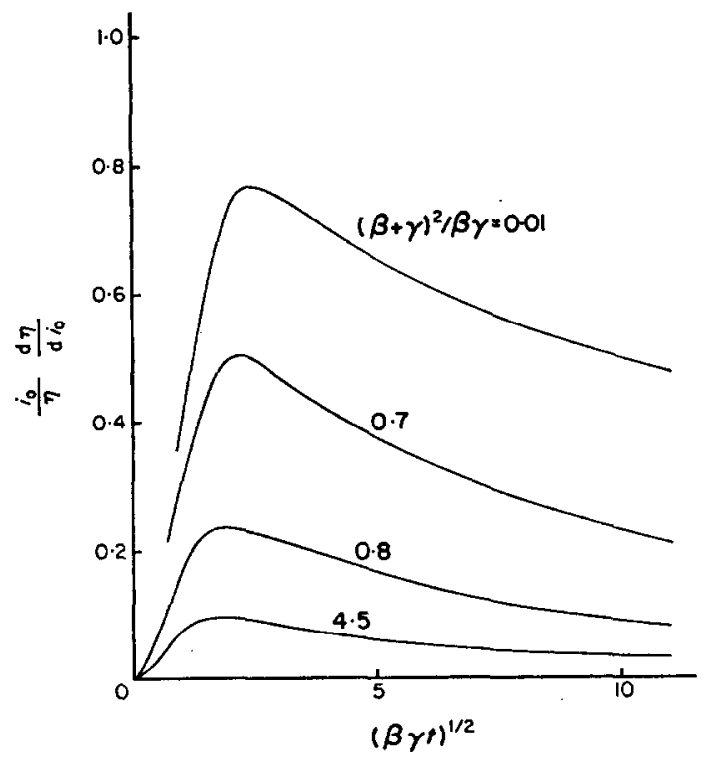

FIG. 1. $\left(i_{0} / \eta\right)\left(\mathrm{d} \eta / \mathrm{d} i_{0}\right) v s(\beta \gamma t)^{1 / 2}$ for different values of $(\beta+\gamma)^{2} / \beta \gamma$.

appears that(6)remains valid if the relative errors in $\left\{1 /\left(C_{\mathrm{Ox}}{ }^{*} \sqrt{ } D_{\mathrm{Ox}}+1 /\left(C_{\mathrm{Red}}^{*} \sqrt{ } D_{\mathrm{Red}}\right)\right\}\right.$ and in $C_{\mathrm{d}}$ are equal, see Fig. 2. Even if the relative error in $C_{\mathrm{d}}$ largely exceeds the relative errors in the other quantities $(\sqrt{ } D$ and $\eta$ ), it can be shown that the optimum time will not differ much from the time condition in (6); the same is true for a large error in $\sqrt{ } D$.

In the usual approach to the galvanostatic step method the time condition in (6) cannot be fulfilled. Equation (4) is of relative cumbersome form for direct application to experimental data. Only experiments under conditions at which the exp erfc's in (4) vanish, can be interpreted. In that case (4) reduces to

$$
\begin{aligned}
& \eta(t)=\frac{2 R T i}{\eta F \pi^{1 / 2}}\left(\frac{1}{C_{\mathrm{Ox}}{ }^{*} \sqrt{ } D_{\mathrm{Ox}}}\right.\left.+\frac{1}{C_{\mathrm{Red}}^{*} \sqrt{ } D_{\mathrm{Red}}}\right) t^{1 / 2}+ \\
& \frac{R T}{\eta F}\left[1 / i_{c}-\frac{R T C_{\mathrm{d}}}{\eta F}\left(\frac{1}{C_{\mathrm{Ox}}{ }^{*} \sqrt{ } D_{\mathrm{Ox}}}+\frac{1}{C_{\mathrm{Red}}^{*} \sqrt{ } D_{\mathrm{Red}}}\right)^{\lambda}\right] .
\end{aligned}
$$

A plot of $\eta(t) v s t^{1 / 2}$ yields a straight line. The value of $i_{0}$ can be found from the intercept of the line with the $\eta(t)$ axis provided that the $C_{\mathrm{d}}$ value is known with sufficient 
accuracy. The simplification of (4) into (7) holds (within 1 per cent), if $\mathbf{4 . 1 1}$

$$
\begin{aligned}
& t>100 / \beta \gamma \text { for slow reactions, ie }(\beta+\gamma)^{2} / \beta \gamma \ll 2 \\
& t>50(\beta+\gamma)^{2} / \beta^{2} \gamma^{2} \text { for fast reactions, ie }(\beta+\gamma)^{2} / \beta \gamma \gg 2 \\
& t>5 / \beta \gamma \text { for the intermediate case }(\beta+\gamma)^{2} / \beta \gamma \sim 2 .
\end{aligned}
$$

A comparison of (8) with (6) shows that the optimum time condition can be attained only in a small region of $(\beta+\gamma)^{2} / \beta \gamma$, where it is about 2 . It can be seen from Fig. 2

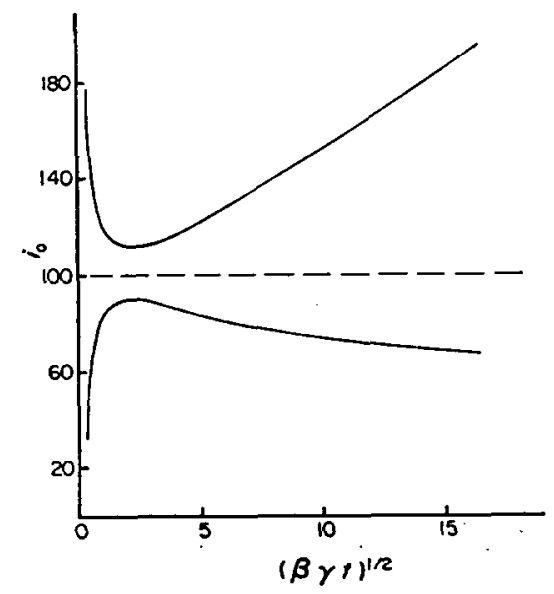

FIG. 2. Influence of errors in $\eta, \sqrt{ } D$ and $C_{d}$ on the measured value of $i_{0}$ when $(\beta+\gamma)^{2} / \beta \gamma=0.80$.

Dashed line, exact value of $i_{0}$, taken to be 100 in arbitrary units.

Upper line, measured value of $i_{0}$ if $\mathrm{d} \eta / \eta=-1 \%, \mathrm{~d} \sqrt{ } D / \sqrt{ } D=-2 \%$ and $\mathrm{d} C_{\mathrm{d}} / C_{\mathrm{d}}=$ $-2 \%$.

Lower line, measured value of $i_{0}$ if $\mathrm{d} \eta / \eta=+1 \%, \mathrm{~d} \sqrt{ } D / \sqrt{ } D=+2 \%$ and $\mathrm{d} C_{\mathrm{d}} / C_{\mathrm{d}}=$

$$
+2 \%
$$

that the evaluation of $i_{0}$ can be performed at least three times more accurate from data in the region of the $\eta / t$ curve where $t$ is about $4 / \beta \gamma$ than from data in the region where (7) is valid. For faster reactions, see ( $8 \mathrm{~b})$, the methodology, based upon (7), is still more inferior, as $t$ must be larger than $50 \mathrm{~m} / \beta \gamma, m$ being $(\beta+\gamma)^{2} / \beta \gamma \gg 2$.

\section{NUMERICAL ANALYSIS OF GALVANOSTATIC STEP MEASUREMENTS}

In view of the time condition, represented by (6), a methodology of analysing the galvanostatic step measurements must be developed, taking into account the exp erfc in (4). Therefore we propose a method based on the use of nomograms. As has been pointed out before, (4) can be simplified by writing it in dimensionless form by the substitution of $t=k / a^{2}$. In this form (4) is dependent only on $k$ and $(\beta+\gamma)^{2} / \beta \gamma$, see (5a) and (5b). In Table 1 the values of the dimensionless quantity $a^{2} C_{d} \eta\left(k / a^{2}\right) / i$ are listed as a function of the dimensionless parameter $k=a^{2} t$ for several values of $(\beta+\gamma)^{2} / \beta \gamma$. The procedure of determining the exchange current density by means of Table 1 is as follows. First the value of

$$
\left(\frac{1}{C_{\mathrm{Ox}}{ }^{*} \sqrt{ } D_{\mathrm{Ox}}}+\frac{1}{C_{\mathrm{Red}}^{*} \sqrt{ } D_{\mathrm{Red}}}\right)
$$




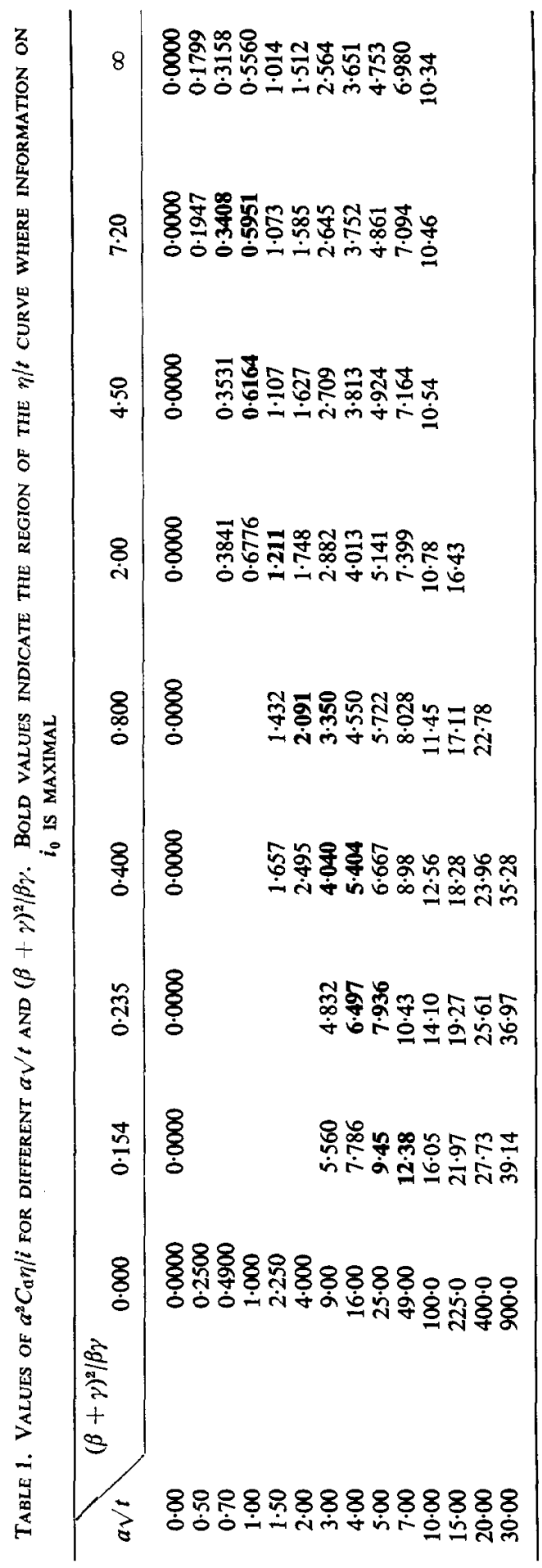


must be obtained from measurements at long pulse times obeying the condition given in (8). Secondly the value of $C_{\mathfrak{d}}$ must be determined, eg from pulse measurements at very short times. Then the value of $a$ is known. At some point of the $\eta / t$ curve the value of $a^{2} C_{\mathrm{d}} \eta(t) / i$ must be calculated and compared with the values in Table 1. Interpolation between the tabulated values can be performed by plotting the values of $a^{2} C_{\mathrm{d}} \eta(t) / i$ at constant $a \sqrt{ } t$ against $\log (\beta+\gamma)^{2} / \beta \gamma$. From the obtained $(\beta+\gamma)^{2} / \beta \gamma$ value the exchange current density can be found with

$$
i_{0}=n a\left(\frac{1}{C_{0 \mathrm{x}}{ }^{*} \sqrt{ } D_{\mathrm{Ox}}}+\frac{1}{C_{\mathrm{Red}}^{*} \sqrt{ } D_{\mathrm{Red}}}\right)^{-1} \frac{(\beta+\gamma)^{2}}{\beta \gamma},
$$

$n$ being the number of electrons involved in the electrode reaction.

In Table 1 nomograms are listed for types of electrode reactions with $(\beta+\gamma)^{2} / \beta \gamma$ between $0 \cdot 153$ and $7 \cdot 2$. The information on $i_{0}$ of types of electrode reactions with lower $(\beta+\gamma)^{2} / \beta \gamma$ values is sufficiently large to evaluate the exchange current density with the method based on (7). Exchange current densities with $(\beta+\gamma)^{2} / \beta \gamma$ exceeding $7 \cdot 2$ are not likely to be determined, as the information on $i_{0}$ is too small in that case. Bold values in Table 1 indicate the value of $a \sqrt{ } t$ for which $t \sim 4 / \beta \gamma$, where information on $i_{0}$ for that type of reaction is maximal.

It should be noted that Table 1 with the dimensionless parameters $a^{2} C_{\mathrm{d}} \eta(t) / i$ and $a \sqrt{ } t$ can be changed easily into a table with the also dimensionless parameters $C_{\mathrm{d}} \eta(t) /$ it and $a^{2} t$. Such a table has probably the advantage that the experimentally obtained $\eta / t$ curve does not need to be transformed in a $\eta / t^{1 / 2}$ curve, but this a matter of personal choice.

This method based on the use of nomograms has the following advantages over the method based on (7). The accuracy and the applicability of the method is at least three times better, since experimental data can be used in the region of the $\eta / t$ curve where information on the kinetics of the electrode reaction is maximal. Systematic errors due to ignoring the exp erfe are avoided. The occurrence of a second faster reaction could be detected; ie if the obtained value of $(\beta+\gamma)^{2} / \beta \gamma$ is dependent on $a \sqrt{ } t$, which means that the assumption of a one-step electrode reaction as the basis for (4) is not justified in such a case.

\section{NUMERICAL ANALYSIS OF COULOSTATIC IMPULSE MEASUREMENTS}

In the coulostatic impulse relaxation method an impulse of small known charge $q$ is applied to an electrolytic cell. The excursion of the cell potential from its initial equilibrium value is then observed after cessation of the impulse. The general equation describing the potential/time relation is ${ }^{5,6}$

$$
\eta(t)=\frac{\eta_{0}}{\gamma-\beta}\left[\gamma \exp \beta^{2} t \operatorname{erfc} \beta \sqrt{ } t-\beta \exp \gamma^{2} t \operatorname{erfc} \gamma \sqrt{ } t\right]
$$

where $\eta_{0}=q / C_{\mathrm{d}}$ and $\beta$ and $\gamma$ are defined by (4a).

Equation (10) is, like (4), relatively cumbersome for direct application to experimental data because of the occurrence of the exponential error-function complement. If the influence of diffusion is ignored, (10) takes the more convenient form

$$
\eta(t)=\eta_{0} \exp (-\beta \gamma t) \text {. }
$$

On the basis of this equation $i_{0}$ is evaluated in the usual coulostatic impulse technique. 
From a plot of $\ln \eta(t)$ against $t$ the value of $\beta \gamma$ is obtained, from which $i_{0}$ can be deduced if the value of $C_{\mathrm{d}}$ is known. Since diffusion is neglected in (11), it is obvious that this method is limited to the study of relatively slow reactions, see also Fig. 3. Faster reactions can be studied only if the exponential error-function complements in (10) are also taken into account. This can be performed by means of nomograms in a similar way as has been described for the galvanostatic step method. Equation (10), written in a dimensionless form by substituting $t=k / a^{2}$ ( $a$ being defined by (5c)), is a function of only $k$ and $(\beta+\gamma)^{2} / \beta \gamma$, as can be shown by expansion(of (10) for long and for short times: for long times, ie large values of $k$,

$$
\frac{\eta(t)}{\eta_{0}}=\frac{1}{\pi^{1 / 2}}\left[k^{-1 / 2}-\left(1-\frac{2 \beta \gamma}{(\beta+\gamma)^{2}}\right) k^{-3 / 2}+\ldots\right],
$$

and for short times, ie small values of $k$,

$$
\frac{\eta(t)}{\eta_{0}}=1-\frac{(\beta+\gamma)^{2}}{\beta \gamma} k^{2}+\frac{4}{3 \sqrt{ } \pi} \frac{(\beta+\gamma)^{4}}{\beta^{2} \gamma^{2}} k^{3}+\ldots .
$$

With tables of the exponential error-function complements the right hand side of (12) can be calculated for several values of $(\beta+\gamma)^{2} / \beta \gamma$ as a function of the parameter $k=a^{2} t$, Table 2 . The procedure of determining the exchange current density with the nomograms in Table 2 is as follows. The value of

$$
\left(\frac{1}{C_{\mathrm{Ox}}{ }^{*} \sqrt{ } D_{\mathrm{Ox}}}+\frac{1}{C_{\mathrm{Red}}^{*} \sqrt{ } D_{\mathrm{Red}}}\right)
$$

and of $C_{\mathrm{d}}$ obtained from other methods, eg the galvanostatic method, yields the value of $a$. For a point of the $\eta / t$ curve the value of $\eta(t) / \eta_{0}$ can be calculated and compared with the values in Table 2 . Interpolation between the tabulated values is best performed by plotting $\eta(t) / \eta_{0}$ against $\log (\beta+\gamma)^{2} / \beta \gamma$ at constant $a \sqrt{ } t$.

From the $(\beta+\gamma)^{2} / \beta \gamma$ value obtained, the exchange current density can be obtained with (9). Bold values in Table 2 indicate the value of $a \sqrt{ } t$ for which $t \sim 1 / \beta \gamma$, ie the kinetically most useful region of the $\eta / t$ curve in the case of the coulostatic method. Nomograms are listed in Table 2 for types of electrode reactions with $a(\beta+\gamma)^{2} / \beta \gamma$ from $0 \cdot 01$ to $7 \cdot 2$.

At the lower $(\beta+\gamma)^{2} / \beta \gamma$ values the exchange current density could also be evaluated with the method based on (11), Fig. 3a. The latter method would fail for types of electrode reactions with a larger $(\beta+\gamma)^{2} / \beta \gamma$ value, Fig. $3 \mathrm{~b}$. Therefore we conclude that the presented method, using the nomograms in Table 2, enhances the limit of the coulostatic impulse method by a factor of 100 .

FARADAIC IMPEDANCE METHOD

The real $\left(Z^{\prime}\right)$ and the imaginary $\left(Z^{\prime \prime}\right)$ component of the cell impedance, given by the expressions

$$
Z^{\prime}-R_{\Omega}=\frac{\theta+\sigma \omega^{-1 / 2}}{\left(C_{\mathrm{d}} \sigma \omega^{1 / 2}+1\right)^{2}+\omega^{2} C_{\mathrm{d}}^{2}\left(\theta+\sigma \omega^{-1}\right)^{2}}
$$

and

$$
Z^{\prime \prime}=\frac{\omega C_{\mathrm{d}}\left(\theta+\sigma \omega^{-1 / 2}\right)^{2}+\sigma \omega^{-1 / 2}\left(\omega^{1 / 2} C_{\mathrm{d}} \sigma+1\right)}{\left(C_{\mathrm{d}} \sigma \omega^{1 / 2}-1-1\right)^{2}+\omega^{2} C_{\mathrm{d}}^{2}\left(\theta+\sigma \omega^{-\frac{1}{2}}\right)^{2}}
$$




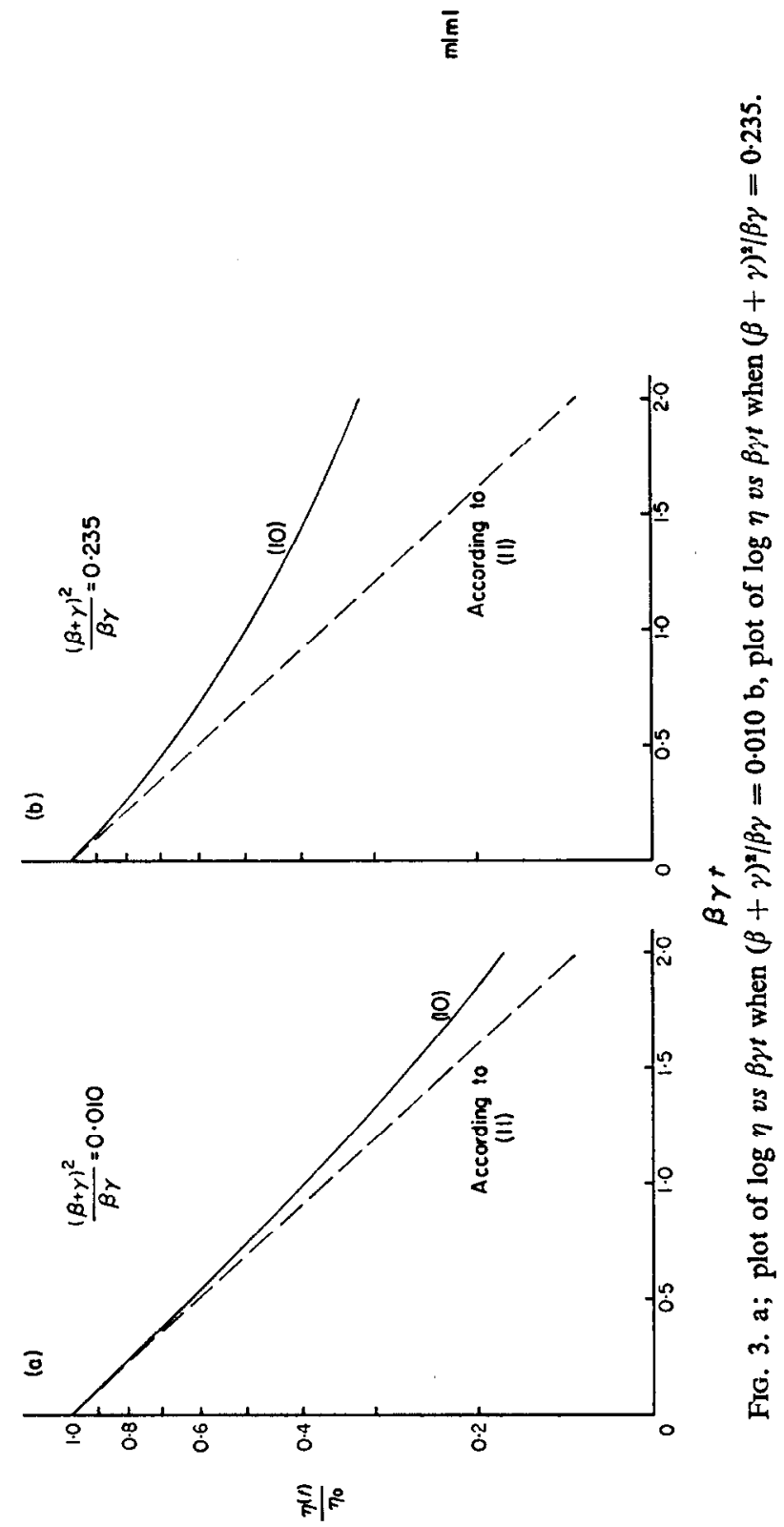




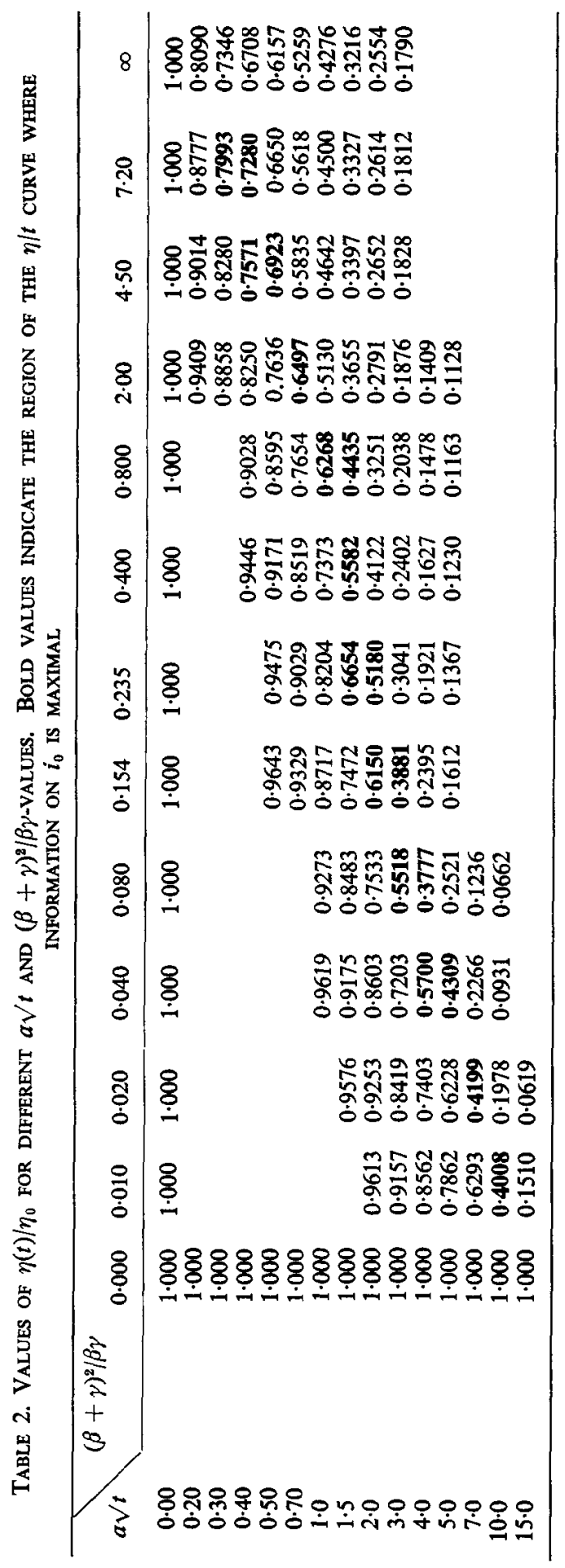


where

$$
\theta=\frac{R T}{n F i_{0}} \quad \text { and } \quad \sigma=\frac{R T}{n^{2} F^{2} \sqrt{ } 2}\left(\frac{1}{C_{0 \mathrm{x}}{ }^{*} \sqrt{ } D_{\mathrm{Ox}}}+\frac{1}{C_{\mathrm{Red}}^{*} \sqrt{ } D_{\mathrm{Red}}}\right)
$$

can be written in a dimensionless form, similar to (5) and (12), by the substitution of $\omega=k^{2} / C_{\mathrm{d}}^{2} \sigma^{2}$,

$$
\frac{Z^{\prime}-R_{\Omega}}{\sigma^{2} C_{\mathrm{d}}}=\frac{\theta / \sigma^{2} C_{\mathrm{d}}+1 / k}{(k+1)^{2}+k^{\mathbf{4}}\left(\theta / \sigma^{2} C_{\mathrm{d}}+k\right)^{2}}
$$

and

$$
\frac{Z^{\prime \prime}}{\sigma^{2} C_{\mathrm{d}}}=\frac{k^{2}\left(\theta / \sigma^{2} C_{\mathrm{d}}+1 / k\right)^{2}+1 / k(k+1)}{(k+1)^{2}+k^{4}\left(\theta / \sigma^{2} C_{\mathrm{d}}+1 / k\right)^{2}}
$$

Maximal information on $i_{0}$ with the faradaic impedance method is obtained under the condition (see Fig. 4 and (2b))

$$
\frac{\mathrm{d}}{\mathrm{d} \omega} \frac{\theta}{|\vec{Z}|} \frac{\mathrm{d}|\vec{Z}|}{\mathrm{d} \theta}=0 .
$$

This equation has been solved numerically with the help of (14a) and (14b) for the same $2 \sigma^{2} C_{\mathrm{d}} / \theta=(\beta+\gamma)^{2} / \beta \gamma$ values as given in Fig. 1. The results are presented graphically in Fig. 5. Maximum information on $i_{0}$ with impedance methods is obtained if

$$
\omega \sim \frac{1}{3 \theta C_{\mathrm{d}}},
$$

almost independent of the value of $2 \sigma^{2} C_{d} / \theta$. Comparing Fig. 1 with Fig. 5 one can see that the impedance method differs in theoretical aspect only slightly from the galvanostatic step method.

A table for the impedance method, similar to those for the galvanostatic step and the coulostatic impulse method, can be constructed with the help of (14a) and (14b). However, the need for such a table is not so compulsary as for the galvanostatic step and coulostatic impulse methods, since the experimental data obtained from the faradaic impedance method can be interpreted for each frequency without simplifications of the exact equations by means of the vector-construction method ${ }^{7}$ or by the complex-plane method. ${ }^{8}$

\section{EXPERIMENTAL TECHNIQUE AND RESULTS}

The improvement of the single-step and the coulostatic impulse method brought about by using the numerical tables in this paper will be illustrated by measurements with the $\mathrm{Cd}^{2+} / \mathrm{Cd}(\mathrm{Hg})$ electrode in $\mathrm{M} \mathrm{NaClO}_{4}$ and the $\mathrm{Hg}_{2}{ }^{2+} / \mathrm{Hg}$-electrode in $\mathrm{M} \mathrm{HClO}_{4}$.

The electrical set-up and apparatus for the single-step method have been described elsewhere.9 For the sake of convenience the same set-up has been used for the coulostatic impulse method. The duration of mcasurcments should then be limited to times so small that no appreciable discharge current flows through the galvanostatic resistor.

Measurements were performed with a two-indicator-electrode cell to avoid interferences due to non-linearities of the current/voltage relation at high overvoltages. ${ }^{10}$ 


\section{$\mathrm{Cd}^{2+} / \mathrm{Cd}(\mathrm{Hg})$ electrode in $\mathrm{M} \mathrm{NaClO}_{4}$ at $\mathrm{pH} 4$}

In a recent paper ${ }^{11}$ we have published the kinetics of this reaction using the singlestep method and analysing the data by means of the approach of Berzins and Delahay, ${ }^{2}$ (see also (7) of this paper). The same data and other data obtained from the more kinetically useful region of the $\eta / t$ curve were analysed with Table 1 in this

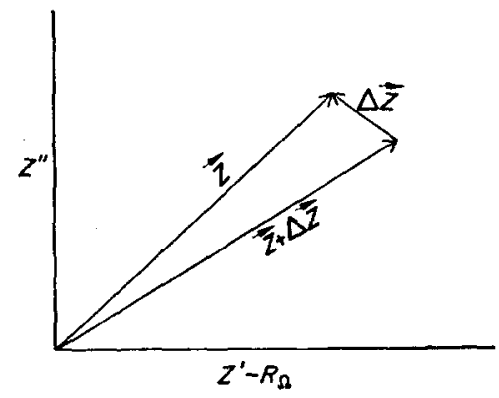

FIG. 4

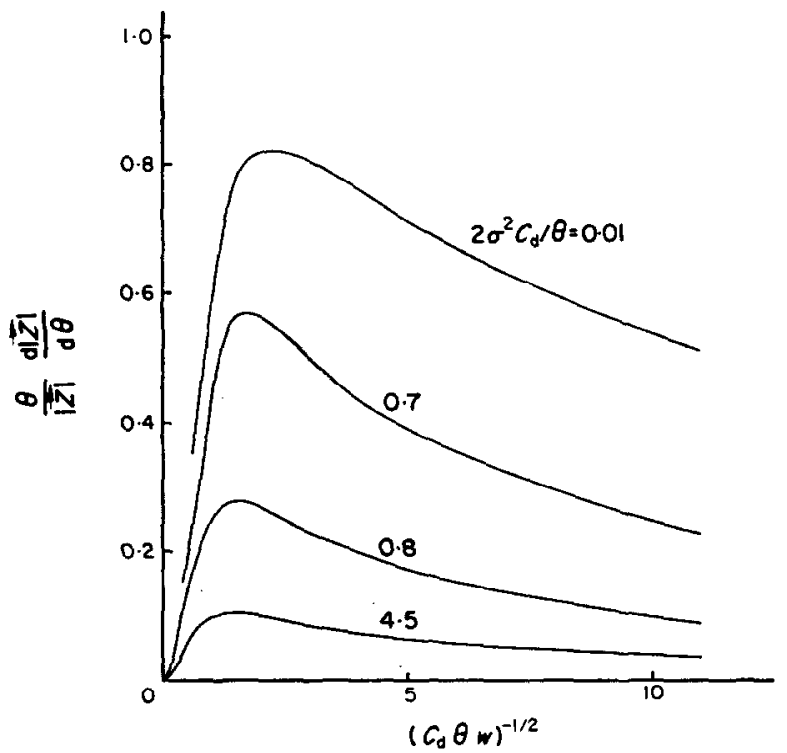

Fio. 5. $(\theta /|\vec{z}|) /(\mathrm{d}|\vec{z}| / \mathrm{d} \theta)$ as a function of $\left(C_{\mathrm{d}} \theta \omega\right)^{-1 / 2}$ for different values of $2 \sigma^{2} C_{a} / \theta$.

paper. A typical example is given in Table 3. The value of $C_{\mathrm{d}}$ has been obtained from measurements at short pulse lengths of about $1 \mu \mathrm{s}$, whereas the value of

$$
\left(\frac{1}{C_{\mathrm{Ox}}^{*} \sqrt{ } D_{\mathrm{Ox}}}+\frac{1}{C_{\mathrm{Red}}^{*} \sqrt{ } D_{\mathrm{Red}}}\right)
$$

has been determined from measurements at large pulse lengths obeying the conditions represented in (8). The exchange current densities, measured at other concentrations are listed in Table 4. These values are more accurate than the values calculated with the method based upon (7). As a consequence a more reliable value of $k_{8 \mathrm{~h}}$ and $\alpha$ 
than that given before ${ }^{11}$ can be determined,

$$
k_{\mathrm{sh}}=0.46 \pm 0.03 \mathrm{~cm} / \mathrm{s} \text { and } \alpha=0.80 \pm 0.02
$$

It appears from Table 3 that the $i_{0}$ values obtained are independent of $a \sqrt{ } t$, which means that the basic assumption of a one-step electrode reaction is justified. The same reasoning is valid in the case of the coulostatic impulse method. The good agreement of the two methods is to be noted.

TABle 3. Data ON THE SYStem $\mathrm{Cd}^{2+} / \mathrm{Cd}(\mathrm{Hg})$ in $\mathrm{M} \mathrm{NaClO}$, at pH 4

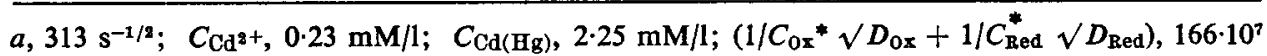
cm.s $/ \mathrm{mol} ; C_{\mathrm{d}}=29 \cdot 10^{-6} \mathrm{~F} / \mathrm{cm}^{2}$

\begin{tabular}{rrrrrrr}
\hline & \multicolumn{2}{c}{ Single-step } & \multicolumn{3}{c}{ Coulostatic-impulse } \\
\hline$a \sqrt{ } t$ & $a^{2} C_{\mathrm{d}} \eta / \mathrm{i}$ & $(\beta+\gamma)^{2} / \beta \gamma$ & $\mathrm{mA} / \mathrm{cm}^{2}$ & $\eta(t) / \eta_{0}$ & $(\beta+\gamma)^{2} / \beta \gamma$ & ${\mathrm{mA} / \mathrm{cm}^{2}}^{i_{0}}$ \\
\hline 0.7 & & & 0.765 & 0.80 & 30 \\
1.0 & & & 0.622 & 0.82 & 31 \\
1.5 & 2.10 & 0.79 & 30 & 0.438 & 0.82 & 31 \\
2.0 & 4.52 & 0.81 & 30.5 & & & \\
4.0 & 11.35 & 0.90 & 34 & & & \\
10.0 & 17.05 & 0.82 & 31 & & & \\
15.0 & & & & & & \\
\hline
\end{tabular}

TABle 4. Kinetic data on the $\mathrm{Cd}^{2+} / \mathrm{Cd}(\mathrm{Hg})$ electrode IN $\mathrm{M} \mathrm{NaCl} \mathrm{O} \mathrm{O}_{4}$ AT $\mathrm{pH}=4$

\begin{tabular}{ccc}
\hline $\begin{array}{c}\mathrm{Cd}^{2+} \\
\mathrm{mM} / 1\end{array}$ & $\begin{array}{c}\mathrm{Cd}(\mathrm{Hg}) \\
\mathrm{mM} / 1\end{array}$ & $\begin{array}{c}i_{0} \\
\mathrm{~mA} / \mathrm{cm}^{2}\end{array}$ \\
\hline $0 \cdot 12$ & 2.25 & 19 \\
$0 \cdot 23$ & & 31 \\
0.54 & & 61 \\
0.46 & 1.19 & 53 \\
$1 \cdot 19$ & & 100 \\
2.00 & & 160 \\
\hline
\end{tabular}

$\mathrm{Hg}_{2}{ }^{2+} / \mathrm{Hg}$ electrode in $\mathrm{M} \mathrm{HClO}_{4}$

The exchange current density of this system has been measured by several methods and it is one of the fastest known electrode reactions. Imai and Delahay ${ }^{12}$ reported for $1 \mathrm{mM} \mathrm{Hg}_{2}^{2+}$ an exchange current density of $12 \mathrm{~A} / \mathrm{cm}^{2}$, measured with the faradaic rectification method. Sluyters-Rehbach and Sluyters ${ }^{13}$ conclude from a complexplane analysis that $i_{0}$ must be larger than $450 \mathrm{~mA} / \mathrm{cm}^{2}$ for $1 \mathrm{mM} \mathrm{Hg}_{2}{ }^{2+}$. Matsuda et $a l^{14}$ measured, with the double-pulse method, an $i_{0}$ of about $250 \mathrm{~mA} / \mathrm{cm}^{2}$ for $1 \mathrm{mM} \mathrm{Hg}_{2}{ }^{2+}$. In a recent paper ${ }^{15}$ we have shown that the double-pulse method has not the outstanding possibilities as was thought before. Therefore an $i_{0}$ value of $250 \mathrm{~mA} /$ $\mathrm{cm}^{2}$ for $1 \mathrm{mM} \mathrm{Hg}_{2}{ }^{2+}$ measured with the double-pulse method is questionable. Birke and $\mathrm{Roe}^{16}$ applied a modified single-step technique to the $\mathrm{Hg}_{2}{ }^{2+} / \mathrm{Hg}$-electrode and measured an $i_{0}$ of $350 \mathrm{~mA} / \mathrm{cm}^{2}$ for $1 \mathrm{mM} \mathrm{Hg}_{2}{ }^{2+}$. This value is not consistent with the values derived by means of the faradaic rectification method and the complex-plane method. Therefore we have attempted to confirm their measurements using the single-step method and analysing the data with Table 1 . The results are listed in 
Table 4. The $C_{\mathrm{d}}$ values have been determined also by pulse measurements at short lengths, about $1 \mu \mathrm{s}$, by means of a procedure outlined in a previous paper. ${ }^{11}$ These values agree with the values obtained from measurements with the complex-plane method. However the large inaccuracy of the $C_{\mathrm{d}}$ values at high $\mathrm{Hg}_{2}{ }^{2+}$ concentrations prevents an accurate evaluation of the exchange current densities, whereas at lower $\mathrm{Hg}_{2}{ }^{2+}$ concentrations the values of $(\beta+\gamma)^{2} / \beta \gamma$ of the reaction are too high to be determined. Taking into account the inaccuracy of both the measured value of $C_{d}$ and of $1 / C_{0 x}{ }^{*} \sqrt{ } D_{\mathrm{Ox}}$, we conclude from our measurements that the exchange current density for $0.88 \mathrm{mM} \mathrm{Hg}_{2}{ }^{2+}$ must be larger than $0.6 \mathrm{~A} / \mathrm{cm}^{2}$ and is probably smaller than $2 \mathrm{~A} / \mathrm{cm}^{2}$, see Table 5 .

Table 5. Data on the System $(0.88 \mathrm{mM} / \mathrm{l}) \mathrm{Hg}_{2}{ }^{2+} / \mathrm{Hg}$-electrode IN $\mathrm{M} \mathrm{HClO}_{4}$

\begin{tabular}{|c|c|c|c|c|c|c|c|}
\hline \multicolumn{4}{|c|}{$\begin{array}{l}\text { Upper limit of } i_{0} \text { for } C_{\mathrm{a}}=50 \cdot 10^{-6} \mathrm{~F} / \mathrm{cm}^{2} \\
1 / C_{0 \times}^{*} \sqrt{ } D_{0 \mathrm{x}}=39 \cdot 1 \cdot 10^{7} \mathrm{~cm} \cdot \mathrm{s}^{1 / 2} / \mathrm{mol} \text { and } \\
a=770 \mathrm{~s}^{1 / 2}\end{array}$} & \multicolumn{4}{|c|}{$\begin{array}{l}\text { Lower limit of } i_{0} \text { for } C_{\mathrm{d}}=65 \cdot 10^{-6} \mathrm{~F} / \mathrm{cm}^{2} \text {, } \\
1 / C_{0 \times}^{*} \sqrt{ } D_{0 x}=38 \cdot 3 \cdot 10^{7} \mathrm{~cm} . \mathrm{s}^{1 / 2} / \mathrm{mol} \text { and } \\
a=587 \mathrm{~s}^{1 / 2}\end{array}$} \\
\hline$a \sqrt{ } t$ & $a^{2} C_{\mathrm{d}} \eta(t) / i$ & $(\beta+\gamma)^{2} / \beta \gamma$ & $i_{0} \mathrm{~A} / \mathrm{cm}^{2}$ & $a \sqrt{ } t$ & $a^{2} C_{\mathrm{d}} \eta(t) / i$ & $(\beta+\gamma)^{2} / \beta \gamma$ & $i_{0}\left(\mathrm{~A} / \mathrm{cm}^{2}\right)$ \\
\hline $2 \cdot 0$ & $1 \cdot 61$ & $5 \cdot 4$ & $2 \cdot 1$ & 1.5 & 120 & $2 \cdot 1$ & 0.65 \\
\hline $3 \cdot 0$ & $2 \cdot 73$ & 3.9 & $1 \cdot 6$ & $2 \cdot 0$ & 175 & $2 \cdot 0$ & 0.61 \\
\hline $5 \cdot 0$ & 4.95 & $4 \cdot 0$ & 1.6 & $4 \cdot 0$ & 298 & $2 \cdot 2$ & 0.68 \\
\hline $7 \cdot 0$ & $7 \cdot 13$ & $5 \cdot 5$ & $2 \cdot 2$ & $5 \cdot 0$ & 503 & $2 \cdot 8$ & 0.86 \\
\hline
\end{tabular}

Acknowledgements-This investigation was supported in part by the Netherlands Foundation for Chemical Research (S.O.N.) with financial aid from the Netherlands Organisation for the Advancement of Pure Research (Z.W.O.).

\section{REFERENCES}

1. P. Delahay, Proc. 2nd. Inter. Congr. Polarography, pp. 26-41. Pergamon, London (1960).

2. T. Berzins and P. Delahay, J. Am. chem. Soc. 77, 6448 (1955).

3. V. N. FADDEYEVA and N. M. TERENT'Ev, Tables of Error Function Complements, Pergamon, London (1961).

4. D. InMAN, J. O'M. Bockris and E. BLomgren, J. electroanal. Chem. 2, 506 (1961).

5. W. H. ReINMUth, Analyt. Chem. 34, 1272 (1962).

6. P. DelahaY, J. phys. Chem. 66, 2204 (1962).

7. J. E. B. RaNDLes, Discuss. Faraday. Soc. 1, 11 (1957).

8. M. Sluyters-Rehbach, D. J. Kooljman and J. H. Sluyters, Proc. 3rd Intern. Congr. Polarography, 1964, pp. 135-146. Macmillan, London (1966).

9. D. J. Kooluman and J. H. Sluyiers, Electrochim. Acta 11, 1147 (1966).

10. D. J. Kooluman, M. SluYTers-ReHbach and J. H. SluYTers, Electrochim. Acta 11, 1197 (1966).

11. D. J. Kooluman and J. H. SluyTers, Electrochim. Acta 12, 693 (1967).

12. H. IMAI and P. DeLAhaY, J. phys. Chem. 66, 1108 (1962).

13. M. SluYters Rehbach and J. H. SluYTers, Recl. Trav. Chim. Pays-Bas 83, 983 (1964).

14. H. Matsuda, S. OKa and P. Delahay, J. Am. chem. Soc. 81, 5077 (1959).

15. D. J. Kooljman and J. H. SluYTeRs, J. electroanal. Chem. 13, 152 (1967).

16. R. L. BIRKE and D. K. Roo, Analyt. Chem. 37, 451 (1965).

17. M. Sluyters-RehVACH and J. H. SluYTers, Recl. Trav. Chem. Pays-Bas 83, 967 (1964). 